МЕРКУЛОВ Павел Александрович - доктор исторических наук, профессор кафедры политологии и государственной политики Среднерусского института управления - филиала Российской академии народного хозяйства и государственной службы при Президенте РФ (302028, Россия, г. Орел, б-р Победы, 5a; nauka@orel.ranepa.ru)

ЕЛИСЕЕВ Анатолий Леонидович - кандидат исторических наук, доцент кафедры трудового права и социального обеспечения Среднерусского института управления - филиала Российской академии народного хозяйства и государственной службы при Президенте РФ (302028, Россия, г. Орел, б-р Победы, 5a; eliseev@orel.ranepa.ru)

АРОНОВ Дмитрий Владимирович - доктор исторических наук, профессор кафедры истории правовых учений Орловского государственного университета им. И.С. Тургенева (302026, Россия, г.Орел, ул. Комсомольская, 95; aronovdv@таil.ru)

\title{
СТУДЕНЧЕСКИЕ ПРОФСОЮЗНЫЕ ОРГАНИЗАЦИИ В СИСТЕМЕ ПОЛИТИЧЕСКОГО УПРАВЛЕНИЯ СОВЕТСКОГО ОБЩЕСТВА В ПЕРВЫЕ ГОДЫ СОВЕТСКОЙ ВЛАСТИ: ЭКОНОМИЧЕСКИЕ И ПОЛИТИЧЕСКИЕ УСЛОВИЯ ФОРМИРОВАНИЯ
}

Аннотация. В настоящей статье авторы рассматривают реформы первых лет советской власти в сфере высшего образования в контексте создания принципиально новых условий его функционирования. $B$ частности, были созданы условия для появления профсоюзов в вузовской среде. Первым этапом было формирование профсоюзных организаций преподавателей и сотрудников, впоследствии дополненных студенческими профсоюзами. Их место и роль в системе политического управления предопределили как идеологические установки руководящих органов Советского государства, так и определенная степень прагматизма, стимулировавшая определение в качестве сферы деятельности профсоюзов хозяйственную, бытовую и культурную сферу жизни вузовского сообщества. Авторы анализируют бытовые и политические условия, в которых проходил этап становления вузовских профсоюзов, устанавливают их взаимосвязь с выбором конкретных форм их организационного воплощения.

Ключевые слова: российская революция, Советское государство, реформа высшего образования, пролетаризация студенчества, профсоюзы в системе высшего образования

3 арождение университетских профсоюзов неразрывно связано с процессами, происходившими в России в начале XX в. В годы Первой русской революции, собственно, и возникают первые профсоюзы, и прежде всего в тех отраслях промышленного производства, где исторически степень и концентрации, и солидарности, и степени осознания собственных корпоративных интересов была наибольшей. Речь о создании профсоюзных организаций учащихся не шла, их объединение проходило в форме землячеств, корпоративных организаций научного, учебного типа, касс взаимопомощи. А профсоюз традиционно считался формой объединения, свойственной промышленному пролетариату или, как вариант, наемным рабочим в сельском хозяйстве и сфере услуг. Отчасти это было связано и с тем, что студенчество России было сравнительно малочисленным как в процентном отношении к населению страны, так и в сравнении с их европейскими коллегами. Собственно, и сами студенческие объединения возникали в студенческой среде с огромным трудом, т.к. именно в учащейся молодежи представители органов государственной власти видели ту радикальную среду, которая выступала питательной почвой для революционного ради- 
кализма. Помимо борьбы с экстремистскими течениями в студенческой среде, максимально ограничивалась любая активность, направленная на создание общественных организаций. С большим трудом пробивали себе дорогу научные общества, кассы взаимопомощи, общества, ориентированные на художественное творчество.

События февраля - октября 1917 г., принципиально изменившие место и роль традиционных социальных групп в общественной иерархии, неизбежно вели к радикальному изменению системы социальных лифтов, которые создавались (декларировались) новой властью, и во многом это касалось системы образования в целом и высшего - в частности. Последнее переживало масштабную реформу, ориентированную как на максимальное лишение его элитарности, так и на превращение его в руках новой власти в средство как преобразования социальной структуры общества, так и решения сугубо прикладных задач в сфере кадрового обеспечения иных направлений социального творчества.

Перестройка высшей школы начала осуществляться в процессе деятельности Народного комиссариата по просвещению (далее - Наркомпрос) на основе ряда постановлений и декретов советского правительства, принятых в первый год его существования. Так, декрет Совета народных комиссаров РСФСР (далее - CHК), принятый 2 августа 1918 г., открывал доступ в университеты всем гражданам Советской республики по достижении ими 16-летнего возраста. При этом даже не требовалось предоставление каких-либо документов, подтверждающих окончание средней школы. В высшей школе отменялась плата за обучение (30 сентября 1921 г. Наркомпрос объявил, что введение вузами платы за обучение будет рассматриваться как преступление $\left.{ }^{1}\right)$.

Были ликвидированы ограничения в получении высшего образования женщинами. При этом речь не шла об обеспечении реализации принципа общего равенства в духе его либерального понимания. Важнейшей составной частью новой государственной политики в сфере высшего образования стало соблюдение классового принципа при приеме в вузы. Отмена обязательности предоставления свидетельств об окончании средней школы не отменила разницу в объеме и качестве знаний, необходимых для освоения программы вузовской подготовки. И здесь у представителей свергнутых с вершины социального олимпа социальных групп оставалось заметное преимущество перед получившими карт-бланш детьми трудящихся. В этой связи Наркомпросу было предложено принять неотложные меры, которые обеспечили бы возможность учиться всем, кто происходил из среды пролетариата и крестьянства и изъявил соответствующее желание ${ }^{2}$.

Естественным продолжением этой линии на демократизацию, а точнее, пролетаризацию вузов стало создание при высших учебных заведениях рабочих факультетов (рабфаков) - этих, по словам М.И. Калинина, «специфических творений Октябрьской революции, этого не дала ни одна революция в мире» [Калинин 1960: 306]. Согласно постановлению Наркомпроса от 11 сентября 1919 г. «Об организации рабочих факультетов при университетах», в срок до 1 ноября 1919 г. все вузы РСФСР должны были открыть рабочие факультеты в целях быстрой количественной и качественной пролетаризации высших учеб-

\footnotetext{
${ }^{1}$ Сборникдекретов и постановлений рабочего и крестьянского правительства по народномуобразованию. Вып. 1. М. 1919. С. 57.

2 История профсоюзов России. Этапы, события, люди. М.: Изд-во Академии труда и социальных отношений. 1999. С. 136.
} 
ных заведений ${ }^{1}$ [Донченко, Самоловова 2014]. При комплектовании рабфаков первый опыт участия в непосредственном регулировании базовых составляющих учебного процесса в высшей школе получили и общественные студенческие организации. Весной 1922 г. представители Центрального бюро коммунистического студенчества были введены в состав Центральной приемной комиссии на рабочие факультеты.

Частью этого процесса стала и деятельность Пролеткульта, частью работы которого стало создание так называемых пролетарских университетов. Последние сегодня зачастую путают с классическими университетами, возникавшими как довольно массовое явление в первые годы Советской власти преимущественно в провинциальных городах. Некоторую долю неясности вносят и так называемые народные университеты, возникшие в России в середине первого десятилетия XX в. как форма участия интеллигенции в деле народного просвещения применительно к обучению взрослого населения страны, представлявшего трудящуюся часть социума.

Народная самодеятельность первых лет советской власти давала и своего рода симбиоз этих типов учебных заведений. Так, пролетарским университетам отказывают в праве считаться университетами в традиционном понимании. Определенный резон в этом имеется. Действительно, пролетарские университеты могли считаться таковыми лишь по названию: они создавались в рамках легализовавшегося в России в 1917 г. Пролеткульта. Вплоть до 1919 г. эта организация пользовалась поддержкой государства (в т.ч. и финансовой), но по мере тяготения правящей партии к монополии на власть и в идеологической сфере Пролеткульт быстро ушел на второй план, а впоследствии и вообще исчез из социальной и политической жизни страны.

Строго говоря, Пролеткульт никогда и не претендовал на то, чтобы составить конкуренцию классическим или традиционным университетам в сфере высшего образования. Об этом говорит не только идеология пролеткульта как учения, но и такой знаковый показатель, как структура учебного заведения. Последняя в системе Пролеткульта (по общему программному плану университета) включала три цикла, или курса: подготовительный, основной и специализированный. Фактически содержание программы этих курсов представляло собой нечто среднее между объемом знаний, даваемым средней школой, и политкурсами для взрослых.

Некие промежуточные формы учебного заведения были отмечены при организации Орловского пролетарского университета. Глава Пролеткульта и его идеолог А.А. Богданов отказал ему в праве называться пролетарским (рабочим) университетом. В своей статье «О провинциальных пролетарских университетах», написанной в 1919 г., Богданов указывал, что «он подходит более или менее к типу “народных университетов” и, надо сказать правду, не наиболее совершенного типа. Имеется отдел гуманитарный, с преобладанием словесности и истории; медицинский; затем естественно-математический, где в естественных науках отведено большое место описательной стороне, а в математике даются основы анализа по отвлеченной, обычной программе, даже вне связи с естественно-научными и техническими приложениями; наконец, технический отдел, с подготовительными курсами по низшей математике». Из этого А.А. Богданов делал вывод, что «нельзя признать правильным, когда курсы таких типов, как в... Орле, обозначаются именем “пролетарских университетов”» [Богданов 1924: 263-264].

\footnotetext{
1 Народное образование в СССР. Общеобразовательная школа: сборник документов 1917-1973 гг. М.: Педагогика. 1974. С. 404-405.
} 
Были в те годы и иные, еще более локальные варианты реализации стремления общества к образованию. Однако в настоящей работе нас интересует не тот весьма краткий период самодеятельности в создании многочисленных типов учебных заведений, использующих в своем названии термин «университет», а ситуация с выбором новым российским студенчеством форм реализации своих корпоративных интересов.

В связи с изменением типа финансирования высшей школы, пониманием ее новой властью как мощного рычага социального творчества, усилением контроля государства диктатуры пролетариата над всеми сферами социальной жизни встал и вопрос о формах организации сотрудников высших учебных заведений в новых условиях. Если в отношении административных и технических сотрудников вузов теория и практика государственного строительства советского периода давали вполне конкретный ответ, видя в них представителей профессий, которые вполне подпадали под сферу профсоюзной ответственности, то в отношении профессорско-преподавательского состава и студентов все было отнюдь не так ясно. С одной стороны, власть принимает определенные меры именно в области материального обеспечения преподавательского состава, создавая ЦКУБУ (Центральную комиссию по улучшению быта ученых), КУБУЧ (Комиссию улучшения быта учащихся), вводя так называемые академические пайки ${ }^{1}$, приравнивая ряд вузовских должностей к категориям населения, имеющим право на так называемый красноармейский, или ударный паек ${ }^{2}$. Переписка руководства вузов тех лет с органами местного управления полна именно такими просьбами с указанием на то, что в противном случае дело постановки высшего образования будет обречено на провал 3 . Вновь создаваемые провинциальные вузы в качестве мощного рекламного хода по привлечению столичной профессуры указывали на типы пайков, выдаваемых преподавателям в той или иной губернии, а также на дополнительные, сверхпайковые натуральные выдачи продуктов, дров, мануфактуры, решение квартирного вопроса и т.п. Соответствующие письма на места направлял и нарком просвещения А.В. Луначарский, писавший в губернии о необходимости введения академического пайка для работников высшей школы [Резниченко 2008: 20].

С другой стороны, профессорско-преподавательский состав неоднозначно встретил революционные события 1917 г., и особенно мероприятия по советизации вузов. В этих условиях одним из средств повышения степени контроля над вузовскими коллективами стало создание в них профсоюзных организаций. Так, согласно Положению о местных профкомах, в каждом учебном заведении, где число работающих было не менее 50 чел., должен был создаваться местный комитет. Он избирался из числа членов профсоюза всеми работниками образовательного учреждения. Однако местком объединял не студенческую часть коллектива, в него входили преподаватели, научные сотрудники, работники и служащие [Резниченко 2008: 20]. Структура профсоюзной организации вуза того

1 Государственный архив Орловской области (ГАОО). Ф. Р-1. ОП. 1. Д. 212. Л. 391. Письмо Орловского Губисполкома № 3887 от 11.12.1920 в Губраспред; там же. Л. 392. Письмо ректора ОГУ Н.И. Конрада в Орловский Губисполком № 362 от 09.12.1920.

Размер пайка в провинции мог отличаться в зависимости от города. Так, в Ростове-на-Дону профессор мог получить ежедневно 600 г хлеба, ежемесячно 400 г растительного масла, 200 г сахара, 300 шт. папирос, 200 г мыла, 400 г соли, 1 кор. спичек, 100 г горчицы и 2 л керосина. См.: Государственный архив Ростовской области (ГАРО). Ф. Р-46. ОП. 1. Д. 39. Л. 26.

2 ГАОО Ф. Р-1. ОП. 1. Д. 212. Л. 393-393(об). Письмо ректора ОГУ Н.И. Конрада в президиум Орловского Губисполкома № 393 от 11.12.1920.

3 ГАОО Ф. Р-484. ОП. 1. Д. 1. Л. 69-69(об). Резолюция о Государственном университете, принятая единогласно на Съезде Советов народного образования Орловской губернии 3 июня 1919 г. 
времени определялась тем местом, которое советская власть отводила профсоюзам в рамках формирующейся в стране политической системы. По большому счету, профсоюзы выступали на языке той эпохи «приводными ремнями» от партии (в свою очередь, выступавшей, говоря словами И.В. Сталина, «как своего рода орден меченосцев внутри государства Советского, направляющий органы последнего и одухотворяющий их деятельность») [Сталин 1947] к массам трудящихся, побуждая их строить новый быт, воспитывать новое отношение к труду, организовывать соцсоревнование и т.п. В принципе эти базовые задачи в различных формулировках, с поправкой на язык эпохи будут варьироваться во всех партийных документах, определявших направления деятельности советских профсоюзов.

В 20-е гг. прошлого века применительно к вузам подобной организацией выступал Всероссийский союз работников просвещения и социалистической культуры. Его органы на местах участвовали в решении кадровых вопросов, в т.ч. в выборах руководства вуза, выполняли многочисленные решения советской власти в области кадров (см., например, вопрос об ограничении совместной службы родственников в советских учреждениях - постановление СНК от 2 августа 1918 г. и т.п.), реализовывали принцип уравнительности в заработной плате, ее ориентации на заработок промышленных рабочих и т.п. Подобная ситуация, да и еще в условиях разрушенного революцией и Гражданской войной хозяйства, влияла на весь учебный процесс. Как отмечается в материалах профкомов тех лет, преподаватели активно занимались поисками дополнительного заработка: «Часть преподавателей экономистов и юристов служит в хозорганах, медики усиленно занимаются практикой. На интенсивность учебой работы и самостоятельной исследовательской это отражается очень сильно. Профессора и научные работники теоретики находятся в тягчайшем положении»1.

История сохранила обращения в профком как профессора с ходатайством «о снабжении его суконным картузом ввиду обнищания и невозможности посему приобрести картуз на собственные средства» ${ }^{2}$, так и представление о материальном положении студентов в середине 20-х гг, которое можно составить по данным, например, «Саратовских известий» от декабря 1924 г. Так, среди студентов Саратовского университета не имели соответственно полу собственных брюк и юбок 4,7 \% и 13,9 \% (т.е. студенты носили их по очереди), были студенты, вообще не имевшие белья; $8,7 \%$ учившихся в университете совсем не обедали, питались только всухомятку [Аврус 2001: 52].

В начале 20-х гг. XX в. материальное положение студентов, не имеющих поддержки семьи, было крайне тяжелым даже при наличии у них права на получение государственной (несколько позднее - ведомственной) или профсоюзной стипендии, пайка, одежды, обуви и некоторых других вещей.

Размеры стипендий в 1920-е гг, как отмечалось в советской печати, были ниже официально установленного прожиточного минимума. В отчете ЦБ коммунистического студенчества (апрель 1922 - март 1923 г.) было отмечено, что «тяжелое положение коммунистического и пролетарского студенчества ставит их в необходимость оставления высшей школы». В связи с этим ЦБ коммунистического студенчества ходатайствовало перед Наркомпросом об увеличении как размеров стипендий, так и их числа ${ }^{3}$.

По различным подсчетам в 1923/1924 уч. г., размер госстипендии составлял в 1922 г. 30 руб. дензнаками 1921 г., в 1923 г. - 8 золотых руб., в 1924 г. - 10 руб.

\footnotetext{
${ }^{1}$ ГАРО Ф. 46. ОП. 1. Д. 196. Л. 11.

2 ГАРО Ф. Р-2303. ОП. 1. Д. 23. Л. 9, 26.

3 Отчет Центрального бюро коммунистического студенчества на период с апреля 1922 г. по 1-е марта 1923 г. М. 1923. С. 11; ЦГА СПб. Ф. 2556. ОП. 2. Д. 1641. Л. 12.
} 
Размеры частных стипендий ${ }^{1}$ находились в диапазоне от 15 до 100 руб., но их число в сравнении с государственными было незначительным (в 1924 г. - 2966 частных стипендий) [Банкин 1925: 122]. К концу 1924 г. государственная стипендия выросла до 20 руб., а в 1925 г. - дважды, сначала до 23 руб. в «столицах» и до 17 руб. в «Провинции», а затем до 25 и 20 руб. соответственно ${ }^{2}$. При этом стоимость обеда в студенческой столовой (ЛГУ) из двух блюд в 1923 г. составляла 42 коп., а с января 1924 г. - 23 коп. ${ }^{3}$ В 1924/1925 уч. г. обед в студенческой столовой стоил 30 коп., комната с коммунальными услугами (свет, вода) 5 руб. в месяц, билет на трамвай - 5 коп., папиросы «Ира», «Ява» - 20-25 коп. за пачку, мужской костюм - 30 руб., мужские ботинки - 15 руб. [Андреев 2007: 85; Рожков 2002: 343-344]. В целом же в 1923/1924 уч. г., когда размер государственной стипендии составлял 10 руб., минимальный студенческий бюджет оценивался в 13,9-22 руб. [Банкин 1925: 122-123]. В 1924/1925 уч. г. рост госстипендии не решал материальные проблемы студентов, т.к. даже официальный прожиточный минимум студентов составлял уже от 33,5 до 40 руб. [Дзюба 1925: 37].

Разгрузка угля, колка дров, торговля в разнос, традиционное еще с дореволюционных времен репетиторство - обычные занятия студентов советских вузов той эпохи. При этом высшее образование оставалось платным, хотя размер оплаты и не был чрезмерным, но, тем не менее, он был обременителен для малоимущих. В 1923 г. во всех советских вузах была введена плата за обучение, ее размер составлял 50 руб. в год. Платные места в размере $10 \%$ общего числа входили в общее число мест, запланированных вузу для приема на 1-й курс. Число категорий, освобождаемых от платы за обучение, постоянно росло. В соответствии с постановлением НКП от 19 апреля 1923 г. в группу категорий населения, освобождаемых от платы за обучение, входили: 1) выпускники рабфаков; 2) получавшие зарплату в рамке 17-разрядной тарифной сетки или их иждивенцы; 3) командированные в вуз профсоюзами и пролетарскими организациями; 4) дети преподавателей вузов и работников просвещения, состоящих в профсоюзе; 5) получающие государственную стипендию; 6) инвалиды Гражданской войны; 7) дети административного, командного, военно-санитарного и комиссарского состава, политработников Красной армии и флота 4 .

В 1924 г. плата за обучение в вузе была заметно дифференцирована в диапазоне от 15 до 400 руб. в год в зависимости от географического пояса, рода занятий абитуриента (профессии) и размера его заработной платы. Например, крестьяне, «источником средств которых являлось исключительно сельское хозяйство», платили от 15 до 25 руб., кустари - от 25 до 50 руб., а лица, живущие на нетрудовые доходы, - от 225 до 400 руб. в год 5 .

Обсуждалась эта проблема и на конференциях студенческих профсоюзов. Так, на Второй конференции в апреле 1925 г. было высказано мнение, что необходима дополнительная индивидуальная проверка всех стипендиатов. Этот подход объяснялся наличием категорий учащихся, имеющих низкие доходы, но принадлежащих к так называемому контрреволюционному элементу (дети священников и т.п., которые, по мнению представителя Главпрофобра, под-

\footnotetext{
1 Согласно декрету СНК «О государственных и частных стипендиях для студентов» могли учреждаться так называемые частные стипендии (с 1925 г. они называются хозяйственными).

2 О государственном и местном бюджете на 1925-1926 уч. год. - Еженедельник народного комиссариата просвещения РСФСР. 1925. № 18. С. 2.

3 Воспоминания бывших студентов факультета общественных наук. Л., 1971. С. $216,234$.

${ }^{4}$ Инструкция о введении платности в высших учебных заведениях НКП. - Бюллетень официальных распоряжений и сообщений Народного комиссариата просвещения. 1923. № 23. С. 3-4.

5 Положение о взимании платы в учреждениях НКП от 15 декабря 1924 г. - Еженедельник народного комиссариата просвещения РСФСР. 1925. № 1. С. 2.
} 
нявшего эту тему, не могли позволить обучать детей «за 400 целковых»1. Таким образом, можно говорить о том, что доминирующим основанием при решении вопроса об освобождении от платного обучения в вузе с точки зрения властей стал имущественный, а не классовый ценз, что связано с фактическим признанием достижения главной цели политики - «пролетаризации студенчества» [Андреев 2007: 90].

Одним из общих мероприятий ЦК профсоюза (Всеработпрос) в масштабе страны стала акция января 1922 г., в рамках которой всех членов профсоюза призвали принять участие в сборе средств для наиболее нуждающихся студентов. Акция получила название Недели помощи пролетарскому студенчеству. Проводились подобные акции и в регионах (в частности, в Татарстане) ${ }^{2}$. Надо отметить, что, понимая ситуацию по регионам в целом, органы хозуправления делали акцент не на сознательность рядовых граждан и хозяйствующих субъектов, а зачастую устанавливали фиксированный размер отчислений от доходов предпринимателей и крупных госучреждений. Помимо этой, наиболее эффективной формы, силами волонтеров проводились лотереи, сбор средств по подписным листам. Власти передавали вузам освободившуюся жилую площадь, выделяли лимиты на биржах труда, вводили скидки по коммунальным услугам, организовывали бесплатную врачебную помощь для студентов, вводили новые стипендии.

Новое пролетарское студенчество страны поддерживали самые разные слои советского общества. Общество старых большевиков при ВЦСПС создало как постоянный орган особую комиссию, которая принимала меры к поиску дополнительных средств для удовлетворения потребностей вузов, добивалась увеличения числа хозяйственных стипендий, занималась учреждением студенческих столовых и т.п. ${ }^{3}$

В октябре 1923 г. вновь прошла Неделя помощи пролетарскому студенчеству, позволившая собрать значительные материальные средства. Осенью 1924 г. начало работу Всесоюзное общество помощи пролетарскому студенчеству, которое сыграло заметную роль в улучшении условий жизни и учебы студентов российских вузов. Общество занималось проблемами увеличения числа стипендий, организации общежитий, студенческих столовых, создания льготных условий приобретения студентами учебной литературы и т.д.

В этой ситуации важнейшей задачей профкомов была помощь сотрудникам как денежная, так и продуктами, топливом и т.п. (естественно, речь шла о членах профсоюзов). Наряду с организацией потребительской кооперации, когда речь шла о понятном перечне продуктов питания (сало, мука, молоко, мясо, яйца), встречаются сообщения в духе специфики эпохи. В одном из профкомов южных вузов сохранилась протокольная запись, относящаяся к 1920 г.: «Получено 40 ведер пива, которое роздано служащим университета. Операция принесла 500 рублей барыша» [Резниченко 2008: 15]. Невольно вспоминается объявление из «Золотого теленка» советских классиков И. Ильфа и Е. Петрова: «Пиво отпускается только членам профсоюза» 4 . Впрочем, есть профсоюзные решения, показывающие нам эпоху с другой стороны. В 1921 г. один из вузовских профкомов принял решение, что «недополученный кем-то хлеб должен

\footnotetext{
${ }^{1}$ ЦГЛ СПб. Ф. 6276. Оп. 69. Д. 40. Л. 82. Выступление Покровского на конференции пролетарского студенчества 6 апреля 1925 г.

2 ГАРФ. Ф. 5574. ОП. 1. Д. 6. Л. 38-40. Неделя помощи пролетарскому студенчеству Татарстана.

3 Правда. 1923. 6 февр. [Королева 2005: 106].

4 Ильф И., Петров Е. Золотой теленок. М. 1931. Доступ: http://knigger.org/ilf-and-petrov/02_zolotoi_ telenok/ (проверено 17.08.2017).
} 
оставляться за лицом, не получившим такового в течение 5 дней, и выдаваться по принадлежности в черством виде» 1 .

По мере перехода страны к мирной жизни начинала складываться и новая система взаимодействия партийных, государственных органов и общественных объединений. В постсоветское время утвердился несколько односторонний взгляд на формирование советской политической системы 20-х гг. прошлого века. Согласно ему, крайности тоталитарного варианта сталинского типа, равно как и неискренность и двойная мораль так называемого позднего застоя, были изначально присущи советской политической системе во всех ее звеньях. Вполне возможно, что эти имевшие место в отечественной истории явления действительно в зародыше содержались в самой типологии нового социального строя. Однако принципиальной аксиологической и методологической ошибкой было бы отрицать то, что стало банальным штампом советских времен, - «революционное творчество масс», и известные колебания партийного руководства в выборе путей развития страны. Все это, в т.ч. и внутрипартийная политическая борьба, на определенное время ослабляли внимание партии к месту в политическом механизме государства общественных организаций, в т.ч. и профсоюзов. Эта ситуация продолжалась недолго, однако в этот период мы видим более чем активное участие общественных организаций во всех сторонах жизни учебных заведений. Конечно, это были уже не первые революционные опыты со старостатом, имевшим шанс превратиться в едва ли не внутривузовского диктатора, что, впрочем, начали преодолевать довольно быстро ${ }^{2}$. Однако в начале становления вузовской профсоюзной системы местные комитеты профсоюзов имели более чем реальные рычаги влияния на многие важные вопросы, такие как реальный контроль над законодательством по охране труда, выполнение коллективного договора. Профсоюз выполнял указания органов советской власти по организации коллективов вузов на различные работы (полевые работы, заготовка топлива, работы по развитию вузовской инфраструктуры в рамках так называемых Недель труда, пресловутые коммунистические субботники и т.п.).

Были в то время и так называемые перегибы в духе времени, в т.ч., как ни странно, и в такой сфере, как культурно-массовая работа. В вузах подчас принимались профсоюзные решения, что те, кто не придет на организованный профкомом митинг или концерт, что будет специально фиксироваться при входе, будут лишены пайка [Резниченко 2008: 17]. Непосещение профессорами профсоюзных собраний расценивалось как нежелание принимать участие в строительстве новой Советской республики ${ }^{3}$. Но такова была та эпоха.

Таким образом, можно утверждать, что в первые постреволюционные годы в системе высшего образования России произошли изменения, которые, с одной стороны, привели к кардинальным изменениям в социальном составе как преподавателей и сотрудников, так и студенчества, а с другой - потребовали от правящей элиты выработки эффективных механизмов управления этой частью социума. Спецификой ситуации, во многом повлиявшей на возникновение и формирование студенческих профсоюзов, а также определение их места в иерархии политической системы советского общества, стали те экономические проблемы, которые стали следствием Первой мировой войны, революционных событий 1917 г. и Гражданской войны. Советская власть, очень быстро приоб-

\footnotetext{
${ }^{1}$ ГАРО. Ф. Р-46 Д. 39. Л. 1-2.

2 ГАРФ Ф. А-2306. Оп. 18. Д. 49. Л. 5-5(об). Постановление Народного комиссариата по просвещению «О заведывании студенческими делами и об участии студентов в управлении ВУЗами РСФСР». 18.11.1918.

3 ГАРО Ф. Р-2303. ОП. 1. Д. 23. Л. 1.
} 
ретавшая авторитарный, а впоследствии - и тоталитарный характер, при всем идеологическом и политическом целеполагании была вполне прагматичной. И в новой системе социального управления студенческие профсоюзы очень быстро пройдут трансформацию от агентов политического влияния в студенческой среде до органа, занимающегося преимущественно хозяйственными, бытовыми и культурными проблемами студенческой молодежи.

\section{Список литературы}

Аврус А.И. 2001. История российских университетов: очерки. М.: Московский общественный научный фонд. 85 с.

Андреев Д.А. 2007. «Красное студенчество»в начале 1920-х г2.: дис. ... к.и.н. СПб. 187 с.

Банкин Ф. 1925. Материальное положение студенчества. - Красная молодежкь. № 1. Богданов А.А. 1924. О пролетарской культуре. 1904-1924. Л.; М.: Книга. 344 с. Донченко А.С., Самоловова Т.Н. 2014. Реформирование высшей школы советского государства в декретах и постановлениях партии и правительства (1917-1938 гг.) - Вестник КрасГАУ. № 10. С. 229-235.

Дзюба И. 1925. О стипендиях. - Красное студенчество. № 6-7.

Калинин М.И. 1960. Избранные произведения. В 4 т. М.: Политиздат. Т. 2. 641 с.

Королева В.В. 2005. Состав, быт и социально-экономическое положение студенчества европейской части РСФСР (1921-1932 гг.): дис. ... к.и.н. Орел. 199 с.

Резниченко М.Г. 2008. История профсоюзной организации Ростовского государственного университета. Ростов н/Д: Логос.

Рожков А.Ю. 2002. Жизненный мир молодого человека в советской России 1920-х годов. Краснодар. Т. 1.405 с.

Сталин И.В. 1947. О политической стратегии и тактике русских коммунистов: набросок плана брошюры. - Сочинения. Т. 5. С. 62-87.

MERKULOV Pavel Aleksandrovich, Dr.Sci. (Hist.), Professor of the Chair of Political Science and Public Policy, Central Russian Institute of Management - Orel branch of the Russian Presidential Academy of National Economy and Public Administration (5a Pobedy Blv, Orel, Russia, 302028; nauka@orel.ranepa.ru)

ELISEEV Anatoliy Leonidovich, Cand.Sci. (Hist.), Associate Professor of the Chair of Labor Law and Social Security, Central Russian Institute of Management - Orel branch of the Russian Presidential Academy of National Economy and Public Administration (5a Pobedy Blv, Orel, Russia, 302028; eliseev@orel.ranepa.ru)

ARONOV Dmitriy Vladimirovich - Dr.Sci. (Hist.), Professor of the Chair of History of Legal Studies, Orel State University named after I.S. Turgenev(95 Komsomol'skaya St, Orel, Russia, 302026; aronovdv@mail.ru)

\section{STUDENT TRADE UNION ORGANIZATIONS IN THE SYSTEM OF POLITICAL MANAGEMENT OF THE SOVIET SOCIETY IN THE FIRST YEARS OF THE SOVIET POWER: ECONOMIC AND POLITICAL CONDITIONS OF FORMATION}

Abstract. The article examines the reforms of the first years of Soviet power in the sphere of higher education in the context of creating fundamentally new frames for its functioning that created conditions for the appearance of trade unions in the university environment. The first stage was the formation of trade union organizations of teachers and employees. This system was subsequently supplemented by student trade unions. Their place and role in the system of political management was predetermined both by ideological guidelines of the leading bodies of the Soviet state, and by a certain degree of 
pragmatism that stimulated the definition of the economic, domestic and cultural spheres of life of the university community as a sphere of activity of trade unions. The authors analyze the everyday and political conditions, in which the stage of formation of university trade unions was held, and their interrelations with the choice of concrete form of their organizational embodiment.

Keywords: Russian revolution, Soviet state, reform of higher education, proletarianization of students, trade unions in higher education

УДК 94(470.6)»1930»

ГАДИЦКАЯ Марина Александровна - кандидат исторических наук, доцент кафедры всеобщей истории историко-филологического факультета Сочинского института - филиала Российского университета дружбы народов (354348, Россия, Краснодарский край, г. Сочи, Адлерский район, ул. Куйбышева, 32; marinagaditskay@mail.ru)

\section{ДОМ ИЛИ КВАРТИРА: О ПОПЫТКАХ МОДЕРНИЗАЦИИ СЕЛЬСКИХ АРХИТЕКТУРНЫХ ПРАКТИК В 1930-Х гг. (ПО МАТЕРИАЛАМ ЮГА РОССИИ)}

Аннотация. В статье раскрывается сущность большевистских идей по кардинальному изменению архитектурного облика колхозной деревни, обусловленному проведением сплошной коллективизации. Излагаются обстоятельства, заставившие большевиков отказаться от радикальных проектов жилищного переустройства и согласиться с сохранением индивидуального домостроительства и личного подсобного (приусадебного) хозяйства. Автор рассматривает закрепление сельскохозяйственной артели как основной формы колхозного строительства, ориентацию на традиционную семью, негативное отношение крестьянства к коммунам в качестве факторов, обеспечивших фиксацию в Конституции СССР 1936 г. параметров индивидуального колхозного подворья.

Ключевые слова: большевики, индивидуальное жилье, колхозники, коммуна, коммунальный быт, личное подворье, многоэтажный дом, общежитие

B литературе и общественном сознании коллективизация сельского хозяйства конца 1920-х - 1930-х гг. обычно понимается как процесс ликвидации единоличных крестьянских хозяйств, создания колхозов и модернизации аграрного сектора советской экономики. Вместе с тем в советской и постсоветской литературе осуществлявшиеся в 1930-х гг. многообразные мероприятия культурно-бытового плана, призванные превратить колхозную деревню в подобие социалистического города, не получили достаточного освещения.

Большевики признавали огромную роль жилья в устройстве, функционировании и развитии советского социума, и по их революционному призыву крестьяне, говоря языком документа, «выгнали помещиков с их насиженных мест, в их поместья водрузились совхозы, коммуны, артели и т.д.» [ПанковаКозочкина 2011: 134]. Большевики справедливо предполагали вначале добиться соответствия нового типа жилища новым общественным отношениям. С этой целью революционные романтики создавали в Советской России дома-коммуны, планировали сделать их «образцовыми домами для трудящихся и школой коллективизма, освободить женщину от рабского домашнего труда, приучить людей к самоуправлению и способствовать отмиранию семьи и переустройству быта» [Орлов 2010: 117]. К примеру, в коммуне «Ранняя заря» Донецкого 